\title{
HISTÓRIA E FICÇÃO: O DIÁRIO DE GETÚLIO VARGAS
}

Prof.a Dr. Maria Luíza Ritzel Remédios

PUCRS/BRASIL

\begin{abstract}
By the reading of Getulio Vargas' diary we intend, through this essay, to investigate the relations between history and fiction. At the same time we discuss on questions of autobiographicals'gender and on the level of literality of a personal diary.

Key-words: Getúlio Vargas, History vs Fiction, confession, autobiography
\end{abstract}

\section{Resumo}

Através da leitura do Diário de Getúlio Vargas. pretende-se, neste ensaio, observar as relações entre história ficção ao mesmo tempo em que se discute a questão do gênero autobiográfico e o grau de literariedade de um diário pessoal.

Palavras-chave:Getúlio Vargas, História vs Ficção, confessionalismo, autobiografismo.

Getúlio Vargas inicia seu Diário (1930 - 1942) ${ }^{\mathbf{1}}$, revelando a consciência que tem, de quanto é difícil a relação com o outro, e a necessidade cada vez maior de encontrar-se na solidão de seu interior:

Se todas as pessoas anotassem diariamente num caderno seus juízos, pensamentos, motivos de ação e as principais ocorrências em que foram partes, muitos, a quem um destino singular impeliu, poderiam igualar as maravilhosas fantasias descritas nos livros de aventura dos escritores da mais rica fantasia imaginativa. O aparente prosaísmo da vida real é bem mais interessante do que parece. Lembrei-me que, se anotasse diariamente, com lealdade e sinceridade, os fatos de minha vida como quem escreve apenas para si mesmo, e não para o público, teria aí um largo repositório de fatos a examinar e uma lição contínua da experiência a consultar. (1995, v.1,3).

\footnotetext{
${ }^{1}$ VARGAS, Getúlio. Diário (1930-1942). São Paulo: Siciliano; Rio de Janeiro: Fundação Getúlio Vargas, 1995. 2 v., 1.257 p. Todas as citações serão retiradas dessa edição, sendo indicadas apenas as páginas.
} 
Assim, sem um projeto arquitetado, centrando-se em sua própria pessoa, escreve a cada dia, limitando-se a seguir o curso de sua existência como homem e como político, pormenorizando-a tal qual ela se desenvolve, conforme as transformações de um lento decorrer. Como ele mesmo diz, escreve para si mesmo, o que faz com que não exista necessidade de justificações explícitas, pois conhece a situação que expõe, e focaliza o instante presente, vivido por ele. Também as palavras iniciais do Diário de Getúlio Vargas marcam claramente o pacto que constitui, no texto, a marca da identidade assumida em nível de enunciação.

Parece evidente, pois, que Getúlio Vargas tem muito claro para si, não só a necessidade de autoconhecer-se através do diário, como também a progressiva responsabilidade do homem diante do universo e da sociedade em que vive. Por ter, através da escrita, "um largo repositório de fatos a examinar e uma lição contínua de experiência a consultar" (ibidem), empreende sua tarefa. Se outras qualidades não tivesse, só por isso seu Diário merece ser lido e discutido.

Ponsonby ${ }^{2}$ indaga em seus estudos sobre diários por que eles são escritos e, descartando a idéia de que eles sejam escritos apenas por egoísmo e vaidade, diz que o impulso de registrar o que se julga historicamente relevante é que importa, quando as pessoas tornamse e sentem-se protagonistas e/ou testemunhas de um acontecimento, como se presenciar fosse participar da história e dos rumos de um país. As pessoas que se destacam exercem grande fascínio, predominando, entre os leitores, de que o importante para a História são os grandes acontecimentos e as grandes figuras. Por isso, Ponsonby acredita que os diários, muito mais que outros escritos, revelam as grandezas e as baixezas humanas, o trivial e a miséria dos grandes homens, e mesmo que não revelem nada considerado excepcional ou pelo menos interessante, sempre serão um registro humano diferente, um repositório de fatos que faz pensá-los e analisá-los.

Por tratar-se, então, de um diário, persegue um objetivo claro, que é dar ao eu um corpo de palavra cujo contorno será a história do autor. Phillippe Lejeune, em Le Pacte Autobiographique ${ }^{3}$, estudou o percurso histórico da autobiografia na França e, analisando textos confessionais ou íntimos, alcançou a formulação dos princípios fundamentais do gênero autobiográfico. Sua preocupação era observar a diferença entre o romance autobiográfico e a autobiografia, considerando diferentes níveis de identidade e não identidade entre autor-narrador-personagem. Pode-se, pois, pensar o Diário de Getúlio Vargas a partir da definição de autobiografia proposta por Lejeune "relato retrospectivo em prosa que uma pessoa real faz de sua própria existência, dando ênfase na sua vida individual e, em particular, na história de sua personalidade" ${ }^{\text {. }}$.

\footnotetext{
${ }^{2}$ PONSOBY, Arthur. English diaries: a review of English diaries from the sixteenth to the twentieth century with an introduction on diary writing. London: Methuen \& CO. Lted, 1923.

${ }^{3}$ LEJEUNE, Philipe. Le pacte autobiographie. Paris: Seuil, 1975.
} 
Constata-se que o texto se encaixa perfeitamente no conceito proposto, pois Getúlio Vargas, sujeito histórico, real, faz um relato retrospectivo, a cada dia, da sua própria existência, enfatizando a história de sua personalidade simultaneamente aos fatos políticos de seu governo e da história do País. Observa-se, ainda, que o autor de um diário, para a realização de seu projeto autobiográfico deve recompor a unidade de sua vida através do tempo, o que também fica explícito no Diário, cuja data inicial é 03 de outubro de 1930 e a final é setembro de 1942, um período de doze anos que revelam a tentativa do diarista de reconstituir e decodificar essa vida em sua globalidade. Assim, ao relatar fatos de sua história, Getúlio Vargas, indivíduo, chega a si mesmo, situa-se como é, na perspectiva do que foi.

Desde a notícia da existência do Diário de Getúlio Vargas, a curiosidade do leitor é aguçada, pois ele quer saber como vivia o homem de ação que se preocupou em registrar e comentar a história política de seu tempo; quer saber o que acontecia nos bastidores do governo, durante a Revolução de 30 ou da Segunda Guerra Mundial. A relação entre o leitor e o diarista estabelece-se de forma íntima e enquanto um quer saber quem foi este Presidente do Brasil, o outro quer comentar a história política de seu tempo e contemplar-se no espelho da sua interioridade.

O Diário, suporte formal dum texto de intervenção, é em Getúlio Vargas, como em outros autores, registro de uma voz que nenhuma imposição ou força pode calar, porque ela é a própria voz de um impulso interior e duma liberdade de pensamento. Essa voz tem, no Diário, o tom de confissão marcado quer pela vibração das vitórias alcançadas, quer pelo desânimo dos insucessos, como se pode constatar nas últimas palavras do Diário:

A $1^{\circ}$ de maio desci para o Rio, com o propósito de comemorar esse dia no grande comício dos trabalhadores no Estádio do Vasco da Gama. Um acidente de automóvel imobilizou-me no leito durante vários meses. Só a 27 de setembro regressei a Petrópolis para transportar parte das coisas que ficaram no Rio Negro.

Quantos acontecimentos de grande transcendência ocorreram na vida do Brasil. Aqui chegado, tracei rapidamente estas linhas, dando por encerradas as anotações. Para que continuá-las após tão longa interrupção? A revolta, o sofrimento também mudou muita coisa dentro de mim! (1995, v.2.477).

Getúlio Vargas pretende, declaradamente, verter, no molde do registro cotidiano e datado, o relato de um tempo histórico de grandes convulsões e mudanças. O Diário recobre a Revolução de 30, a impossibilidade do tenentismo, o fracasso da rebelião paulista de 1932, a Intentona Comunista, a implantação do Estado Novo, a Segunda Guerra Mundial, tornando-se um testemunho notável por ser a visão do articulador político que permanece fiel à sua personalidade de homem de ação e intervenção. Apresenta todos os atores do processo revolucionário com o destaque que a História lhe reservou: Osvaldo Aranha, Góis Monteiro, Vergílio de Melo Franco, entre outros. Também João Alberto, Juarez Távora, João Neves da Fontoura e outras figuras importantes do cenário político e dos negócios nacionais vão desfilando pelas páginas do Diário.

${ }^{4}$ LEJEUNE, Philipe. Op.cit. p. 13-46. 
A marcha revolucionária é narrada com pormenores e o diarista revela seu entusiasmo com a adesão do povo brasileiro à revolução. Assim escreve à noite, no trem, seu fascínio pela aprovação do povo brasileiro e sua determinação em não fazer concessões aos donos do poder que ele derrubava pelas armas ${ }^{!}$

Sente-se que a Revolução está triunfante. Nada poderá detê-la (1995: v.1.)

Em todas as estações o povo aglomerava-se, vitoriando os libertadores (1995: v.1. ).

Por mais que se preocupe com o Brasil e pense que ele não lhe reserva surpresas, Getúlio Vargas não perde nunca a capacidade de comoção perante um fato ou uma notícia, sem se deixar vencer pela indiferença e desvelando sempre o sentimento de brasilidade que o envolve. Justamente isso se revela, quando Getúlio Vargas, em outubro de 1934, no registro referente aos dias 2 a 4 , diz o seguinte:

O dia 3 do corrente, aniversário da Revolução, não teve qualquer festividade. Parece até que passou esquecido. Observei-o com amargura. Apenas, nesse dia, tivemos a corrida de automóveis. Foi um espetáculo empolgante: grande multidão, pista dificil, corrida arriscada, alguns acidentes, vários que desistiram da prova em meio. Por fim venceu um brasileiro. Como é forte o sentimento nacional! Junto a mim estavam o embaixador argentino e algumas senhoras. Guardando a atitude de compostura exterior, eu intimamente sentia-me comovido, com receio até de que me saltassem lágrimas se vencesse um estranho. E eu mesmo me analisava, tomado daquela emoção estranha que procurava reprimir.

(Grifo nosso. 1995, v.2, 331)

As palavras grifadas, no texto acima, corroboram-lhe o sentimento de nacionalidade e de orgulho por um brasileiro haver vencido uma prova automobilística, revelando, também, sua personalidade de político que, com diplomacia, reprime os sentimentos para não ferir os "estrangeiros" que o acompanham. Também se, desde as primeiras páginas do Diário, observa-se que Getúlio Vargas escreve para si mesmo, que o eu escreve para o eu, contemplando a alteridade como uma referência tangencial, pois o desejo de justificar-se foi abandonado, o texto acima comprova isso. Mostra que o diarista permanece o ser em sua unicidade na escrita, na autenticidade da enunciação verdadeira que abriga toda a diversidade do $e u$, quando se confessa cheio de emoção escondido sob a máscara da indiferença. A emoção que o faz abrir-se no ato da escrita, trazida pela memória, fá-lo desvelar-se como ator e testemunha da história:

Foi publicado o manifesto de Plínio Salgado. É um ato de acatamento ao governo, pregando a ordem e a união de todos os brasileiros. Os integralistas mais exaltados não queriam que o manifesto fosse publicado, por entender que o mesmo diminuía ou humilhava seu signatário. Apesar de tudo isso desgostou o ministro da Guerra e seu chefe de secretaria, general Benício, que escreveu uma carta de protesto. (1995 v.2, 223) 
As andanças pessoais e familiares ficam registradas, também, no Diário. Diversas experiências do marido, do pai, do amigo, do amante, ali estão. Não poucas vezes, refere-se à sua família e aos amigos de maneira carinhosa, como se pode notar nos apontamentos dos dias 4 e 5 de março de 1933 :

Sábado e domingo deviam ser dias de repouso, mas [não] chegaram a ser. A mulher e os filhos foram para a cama, atacados de gripe. Além da assistência que lhes devia, aproveitei para trabalhar, despachando um longo expediente, principalmente as renomeações da Agricultura, e estudei um pouco.

No sábado, recebi o João Alberto, com quem tratei da representação de classes, de sindicalização e organização política. No domingo, fui a casa onde o Osvaldo está veraneando. Lá encontrei o Virgílio, o Macedo Soares (José Eduardo) e o Edmundo da Luz Pinto. Conversamos sobre vários assuntos e dali fomos a uma casa fronteira onde estava o ministro Melo Franco que nos mandou convidar para um chá. (1995, v. 1,192-3).

A preocupação com os filhos fica marcada em várias páginas, destacando-se, por exemplo, o relato do dia 11 de setembro de 1939:

Embora as preocupações causadas pela guerra e os problemas que ela cria não serem tranqüilizadores, não se deve ser pessimista quanto à marcha dos negócios públicos.

O mesmo não poderei dizer na vida particular. Primeiramente, a doença dos dois filhos menores, depois, o desastre de automóvel de Alzira e Amaral. Segue a Darci para assisti-los, e lá também adoece e é recolhida a um hospital. O filho mais velho, em Berlim, não deseja sair. Tudo isso são motivos de apreensões e de não pequenas despesas. Quanto a mim, dois acidentes desagradáveis perturbam a minha saúde, além da velha doença crônica que progride, acrescida de agudos motivos sentimentais. Mas tudo isso é comigo e, se escrevo aqui, não falo a ninguém. (1995, v.2, 254.).

Registrando quotidianamente tempos de felicidade e de mágoa, os conteúdos emotivos corporificam-se numa linguagem que intensifica a expressividade. A escrita diarística e fragmentária, o centralismo autobiográfico, a função catártica, próprios do gênero, estão explicitados quando o narrador diz "mas tudo isso é comigo e, se escrevo aqui, não falo a ninguém" ou, ainda, quando aponta para a sua solidão e para a espinhosa função de ser presidente:

Todos passeiam, vão aos teatros, divertem-se. Eu fico só, trabalhando. Não me queixo, nem maldigo a sorte. Sorrio apenas dos que supõem que este posto seja um gozo, e que eu esteja aqui para servir-me e não para servir. (1995, v.2, 239.).

Mesmo assim, ao tratar das emoções e de seus estados psíquicos, transpostos para o papel e corporificados pela escrita, Getúlio Vargas mostra, através de um estilo simples, uma inteligência arguta e uma escrita menos pensada e mais sentida. Não há a preocupação com o literário, apenas a atitude confessional que denuncia as contínuas contradições entre o homem amoroso e o político preocupado com as coisas de seu país. Disseca o eu indivi 
dual, mostrando que nele coabitam diferentes eus e demarcando seu lugar na sociedade e na política brasileiras. Acentua-se, através de uma escrita intuitiva e fragmentária, a atitude avaliadora e crítica, que não deixa indefinido o perfil daquele eu que é, no Diário, o outro que poderia ter sido se fossem diferentes as circunstâncias de sua existência.

Ainda assim, o Diário de Getúlio Vargas é uma narrativa orientada muito mais para sua vida pública do que para a privada; mais documental, no sentido de que nela predominam os fatos da esfera do público sobre os da ordem do privado. Um dos aspectos dessa preocupação do diarista reflete-se na difícil atividade diplomática que desenvolve no sentido de convencer o povo brasileiro e as nações americanas e européias de que toma atitudes corretas, como, por exemplo, se constata nas anotações referentes aos dias 13 e 15 de agosto de 1933:

Nesse tempo, a ocorrência mais importante tem sido a questão do arrendamento dos destroyers americanos pelo Brasil. A Argentina, ou antes, o inquieto Saavedra Lamas apresentou sua reclamação ao governo americano, publicando uma nota contrária ao princípio do arrendamento. O Itamarati publicou outra contestando, e eu publiquei outra para explicar o objetivo das negociações numa linguagem mais ao alcance do povo.

Tenho acompanhado, ou antes, estou acompanhando todo o trabalho de chancelaria não só junto a Washington, como junto a Buenos Aires e às outras nações americanas. Parece que a Argentina e a Inglaterra estão empenhadas em estorvar o arrendamento, e o trabalho maior que fazem é junto à própria politica americana: propaganda nos jornais, no Senado, etc., dinheiro e influência política. A Alemanha também se manifestou contra. (1995, v.2, 64).

O painel histórico e político apresentado em poucas linhas destaca a capacidade de Getúlio Vargas em sintetizar os momentos importantes do homem público que tomara decisões arrojadas. Muitos relatos como esse são encontrados ao longo do Diário e, se fazem o retrato de um momento histórico, também demarcam a estatura do homem público.

As alegrias e vicissitudes da vida privada, quando aparecem no Diário, surgem de modo muito breve, e ainda que demonstrem emoção e sentimento, como antes se referiu, quase não permitem o desnudamento do eu. Somente o leitor perspicaz, aquele que procura nas entrelinhas, percebe a sensibilidade que existe naquele que escreve seu diário.

O Diário de Getúlio Vargas pode ser classificado como literatura confessional e de fato insere-se nesse gênero não só por ser um diário, mas também porque o sujeito avalia de forma autocrítica sua posição no mundo: o mundo que deixa nele marcas profundas e que existe em função de um eu que vive e observa o momento histórico-político de seu tempo. Sendo um texto sem perfeição literária, percebe-se que a escrita reflete a sinceridade da vivência desse eu que se confessa. As palavras servem para revelar o "outro que era eu", portanto a centralidade do sujeito narcísico e também a função catártica dessa escrita. Literatura confessional ou não, o Diário de Getúlio Vargas tem, como tantos outros, valor documental, o que, entretanto, não é o mais importante do livro. Importa o sujeito que ele nos 
REMEDIOS, Maria Luíza Ritzel.

revela: homem público que, conforme ele mesmo diz: "gosto mais de ser interpretado do que me explicar". (1995, v.2, 209).

\section{Referências bibliográficas}

VARGAS, Getúlio. Diário (1930-1942). São Paulo: Siciliano; Rio de Janeiro: Fundação Getúlio Vargas, 1995. 2 v., 1.257 p.

PONSOBY, Arthur. English diaries: a review of English diaries from the sixteenth to the twentieth century with an introduction on diary writing. London: Methuen \& CO. Lted, 1923.

LEJEUNE, Philipe. Le pacte autobiographie. Paris: Seuil, 1975. 